\title{
Anomalous Direction of Peri lenticular Aqueous Humor Associated with Retinal Detachment
}

\author{
Battle Zavala Louis Abraham*, Solís Vivanco Adriana, Campos Islas Rosa Valeria and Domínguez Dueñas \\ Francisca
}

National Institute of Rehabilitation, Ophthalmology Service, Mexico

Submission: May 24, 2021; Published: May 27, 2021

*Corresponding author: Battle Zavala Louis Abraham, National Institute of Rehabilitation, Ophthalmology Service, Mexico

\begin{abstract}
Male patient 61 years old previously diagnosed with glaucoma and a LASER application four months before our evaluation. He presented with pain, visual loss of the left eye and headache. In the physical examination he had conjunctival hyperemia, subepithelial corneal edema, flat anterior chamber grade 2, anterior synechiae, cataract, and intraocular pressure of $42 \mathrm{mmHg}$. Ultrasonography demonstrated retina and choroid properly attached. Ultrabiomicroscopy showed anterior iris displacement that had contact with corneal endothelium without being the lens the cause. Maximal medical therapy was initiated and iridotomies performed, nevertheless, the patient had no improvement, hence the diagnosis of malignant glaucoma. Phacoemulsification+ intraocular lens implant+vitrectomy in the left eye was performed, where we found a Rhegmatogenous retinal detachment [1].
\end{abstract}

Causes and treatment of ocular hypertension and flat anterior chamber have been well described. The main diferencial diagnosis are pupillary block, malignant glaucoma, and choroidal hemorrhage. We presented an unusual case of malignant glaucoma that occurred associated with Rhegmatogenous retinal detachment.

Keywords: LASER application; Flat anterior chamber grade 2, Anterior synechiae, Cataract, Intraocular pressure; Pupillary block; Ophthalmological examination

Purpose: To report a clinical case of a grade 2 flat chamber, with ocular hypertension that did not respond to treatment for the usual diagnoses, this being a case of refractory glaucoma, in which a rhegmatogenous retinal detachment was found.

\section{Case Report}

A 61 year-old man presented for examination with progressive visual loss on left eye, pain and cephalea for 4 weeks. He has previous history of Primary Open Angle Glaucoma under treatment with dorzolamide-timolol. He also refers LASER treatment on the left eye to treat a retinal detachment four months before in another institution. On ophthalmological examination the right eye had mild lens opacity, IOP 20mmHG, VA 20/60, open angle Shaffer- 4 classification and an optic nerve excavation of 7/10. The left eye had conjunctival hyperemia, corneal sub-epithelial edema, grade 2 flat anterior chamber, mild lens opacity, IOP 42 $\mathrm{mmHg}$, and VA of hand movement. Fundoscopy was not possible due to media opacity (Figure 1). Ultrasound B-scan reported a phakic eye, dense vitreous hemorrhage, whereas the retina and choroid were intact and flat (Figure 2).
The patient was diagnosed with a pupillary block. Patient was started on triple topical therapy and oral acetazolamide. YAGLASER iridotomies were performed. Patient persisted with ocular pain, flat anterior chamber and IOP on $36 \mathrm{mmHg}$ regardless the patent iridotomies (Figure 3). Ultrasound bio microscopy (UBM) showed a flat anterior chamber due to irido-corneal contact and an anterior lens displacement. Malignant glaucoma diagnosis was then integrated, and the patient underwent Phaco-vitrectomy. Surprisingly, the surgery demonstrated a large retinal detachment with a localized rhegma (RDD) (Figure 4). Postoperatively VA remained on Hand movement, IOP on $16 \mathrm{mmHg}$ with topical timolol, attached retina with optic nerve excavation 9.5/10 (Figures 5 \&6). 


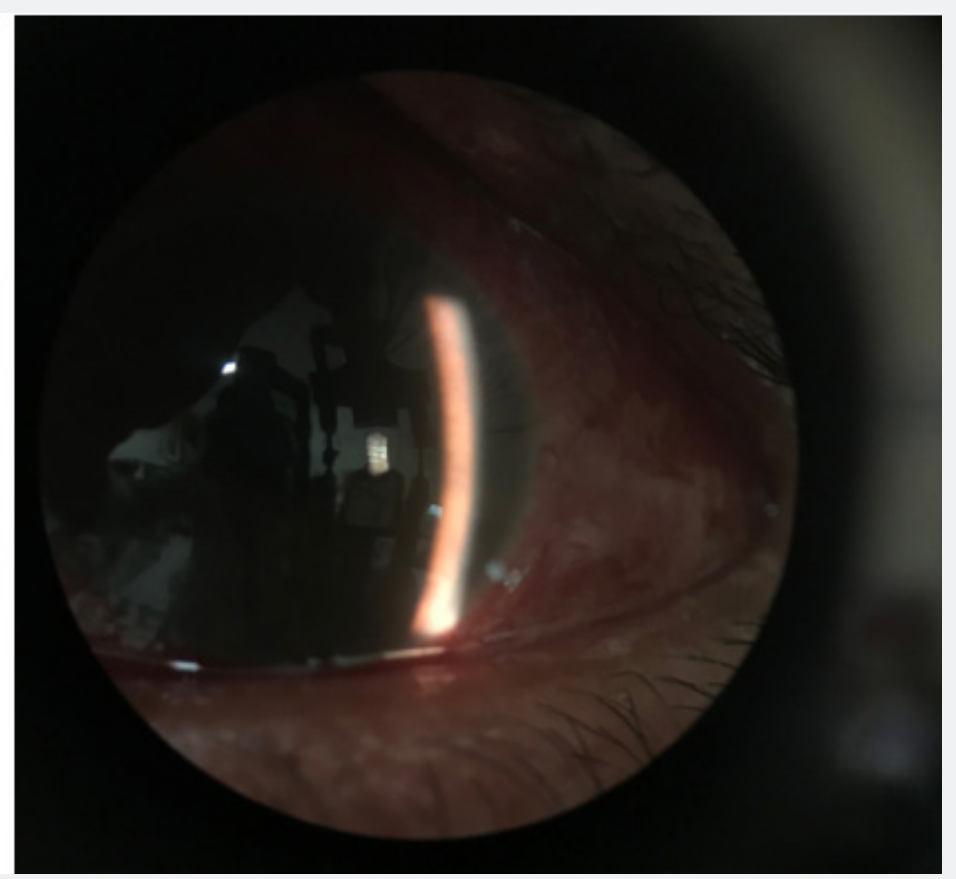

Figure1: Media opacity.

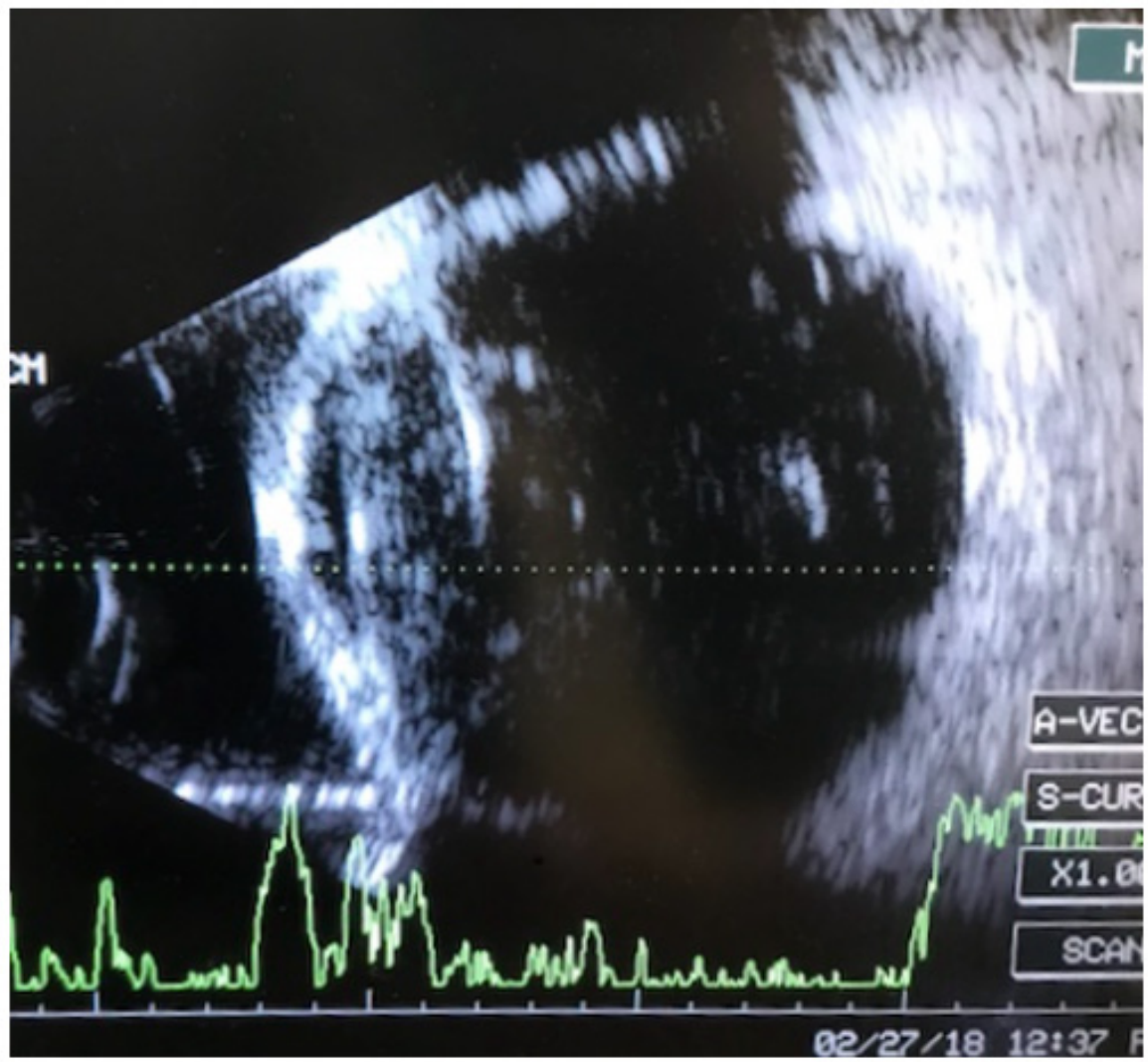

Figure 2: Phakic eye. 


\section{JOJ Ophthalmology}

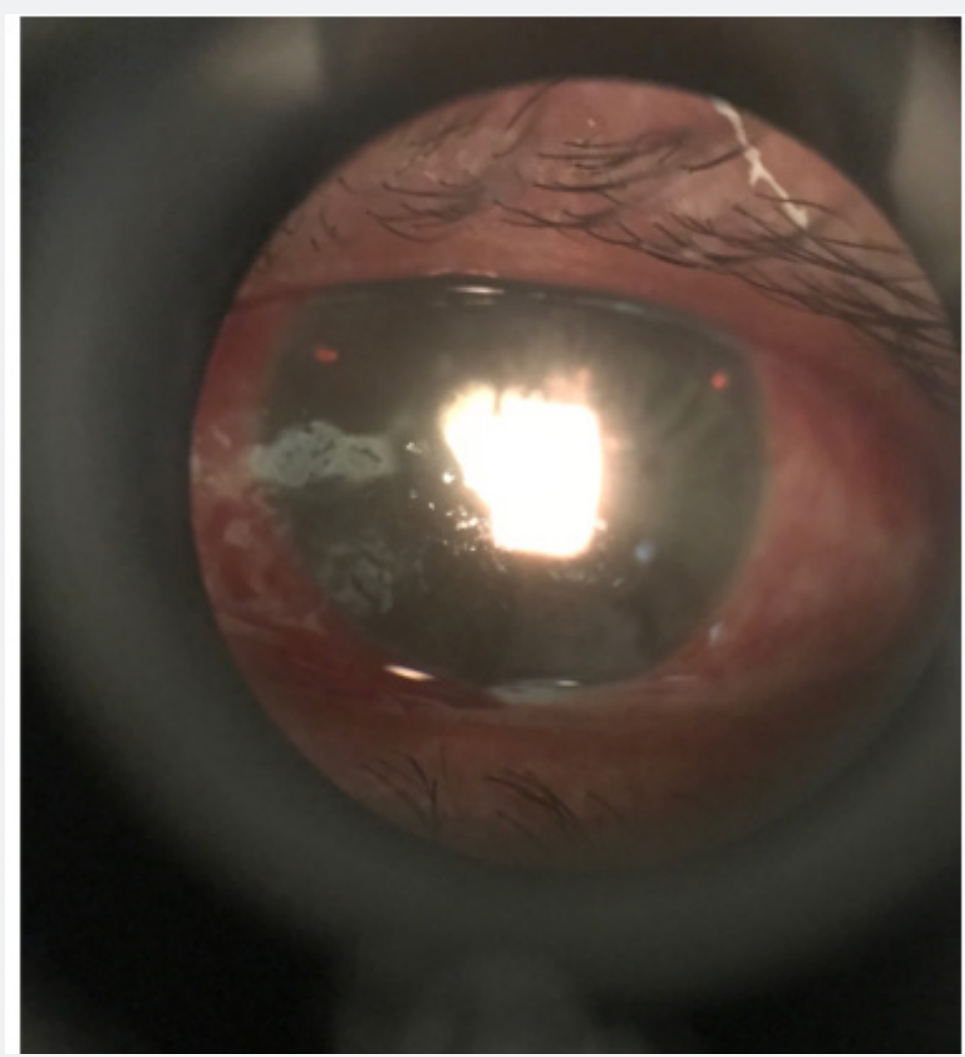

Figure 3: Ocular pain, flat anterior chamber and IOP on $36 \mathrm{mmHg}$ regardless the patent iridotomies.

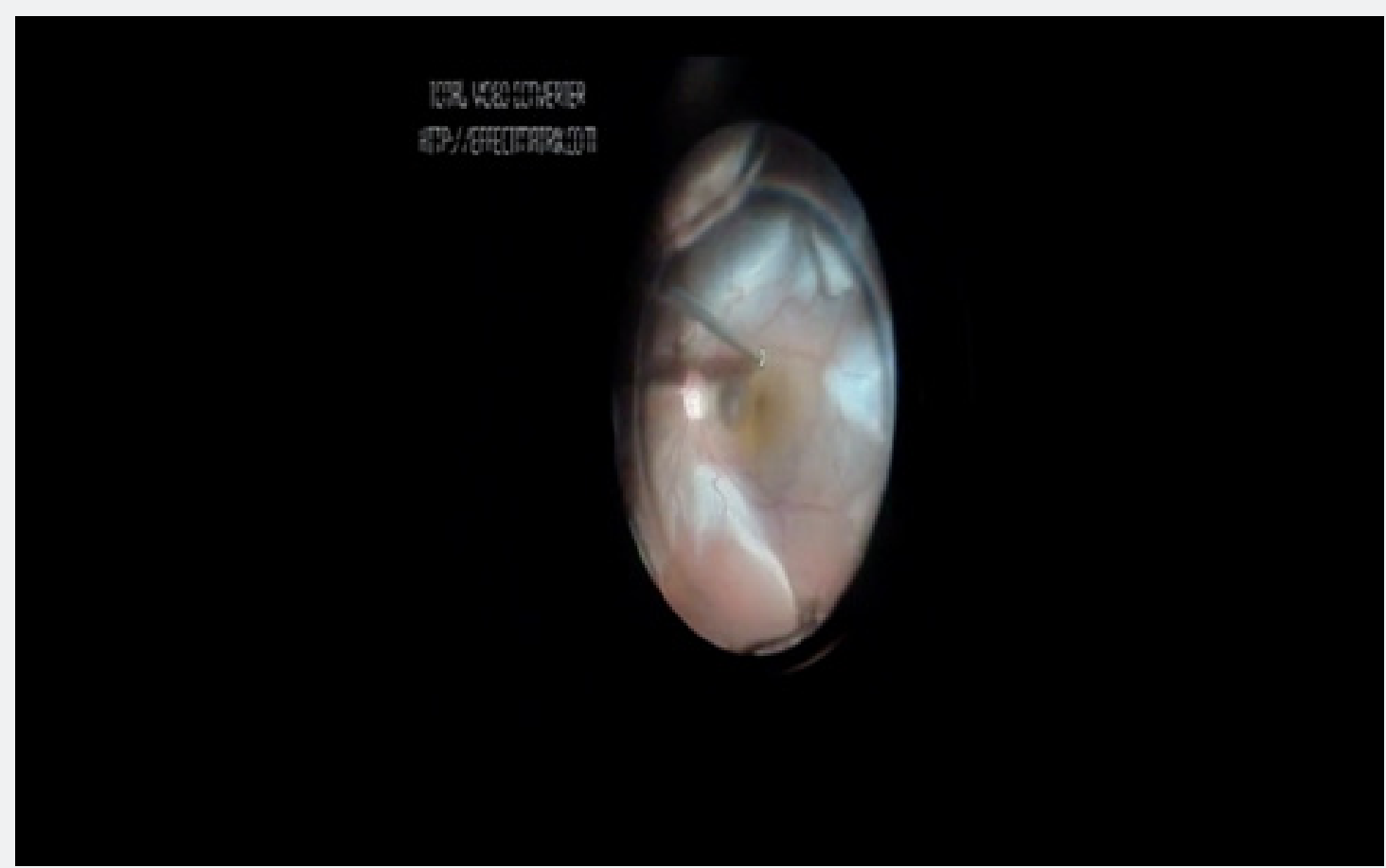

Figure 4: Rhegma (RDD) 


\section{JOJ Ophthalmology}

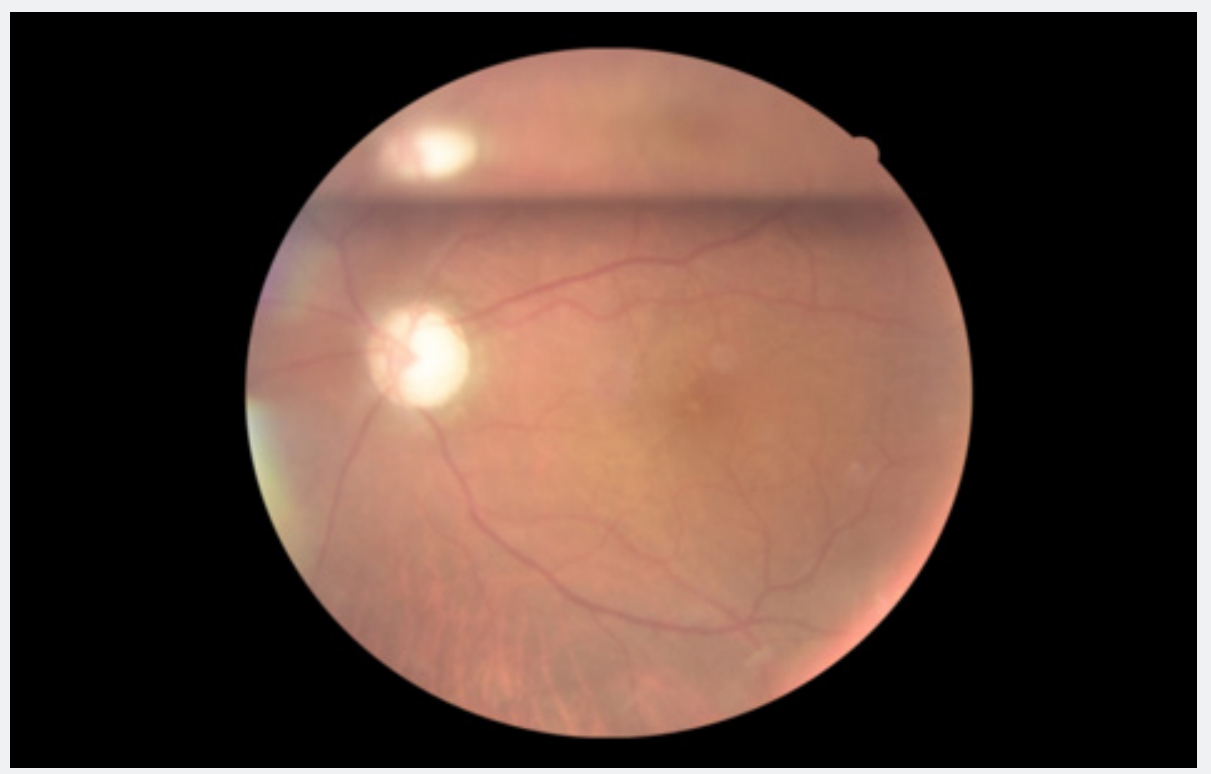

Figure 5: Attached retina with optic nerve excavation 9.5/10.

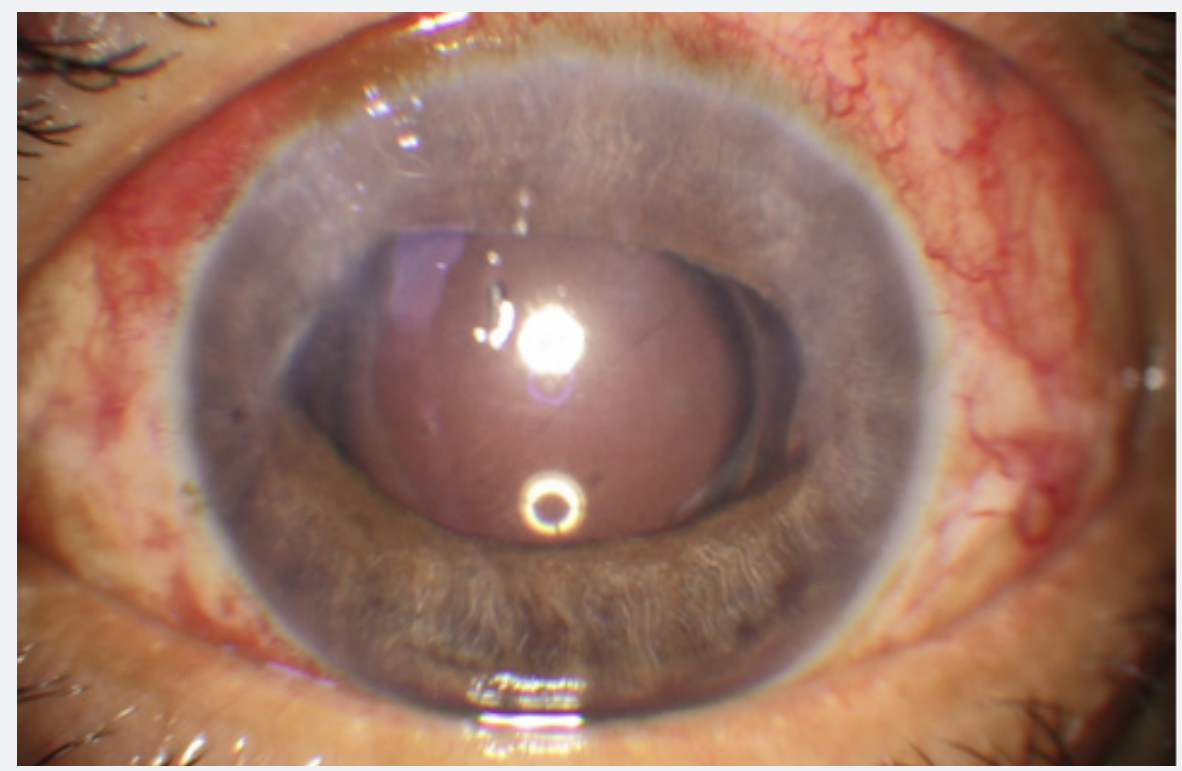

Figure 6: Attached retina with optic nerve excavation 9.5/10.

\section{Discussion}

Malignant glaucoma refers to a rare entity described by Von Graefe on 1869, which was originally reported after an iridectomy. The term "malignant" refers to the bad prognosis and not to a neoplastic entity. Malignant glaucoma is present in 0.4 $0.6 \%$ of cases of primary angle closure glaucoma after incisional surgery. It has been rarely reported as an isolated entity with no apparent unleashing surgical procedures. Its clinical course typically consists of visual loss, pain, flat anterior chamber, ocular hypertension, and corneal edema. Patophysiology is not fully understood. The proposed mechanism is the aqueous humor anterior flux blockage at the ciliary body combined with an alteration of the anterior hyaloid permeability, which causes an aqueous misdirection towards the vitreous cavity or behind and around the lens with the subsecuent anterior displacement of the irido-lens diaphragm, anterior chamber flattening and secondary angle closure. The diagnosis is mainly based on ophthalmological examination and highly supported by ultrasound biomicroscopy. 
In such ancillary test the anterior chamber flattening, angle closure and anterior rotation of the cilliary body are demonstrated. UBM is of high value in differentiating pupillary block from malignant glaucoma, as it can demonstrate the presence of posterior chamber. Rhegmatogenous retinal detachment represents 2-3\% of ophthalmologic causes of patients seeking emergency care. Symptoms include miodesopsy, photopsy and dimished visual acuity. RRD usually present with low IOP and wide-open anterior chamber. The neurosensorial retinal detachment is accompanied by a loss of continuity in its whole layers. Low intraocular pressure in this scenario may be due to 1) diminished aqueous humor production and 2) the Rhegma itself becomes an additional pathway for aqueous humor drainage towards choroidal circulation [2-12].

Ultrasound B-scan shows variable motility, but always less than that of the vitreous membranes. RRD are highly reflective with a chord-like appearance and adhered to the optic disc. Flat RDD may be hard to demonstrate. Initially our case had the clinical presentation of a pupillary block and was therefore treated as it is described. Given the lack of response to such treatment, our diagnostic approach included an UBM and a consecutive Ultrasound B-scan, which helped us discard pupillary block, phacomorfic glaucoma and choroidal hemorrhage. Clinically, the patient cursed with a malignant glaucoma without an obvious triggering cause. During the surgical treatment, a vitreous hemorrhage and a RDD were found. We hypothesized that a hemorrhagic vitreous detachment triggered the clinical course with a concomitant RDD on the site the patient had a previous LASER treatment, maybe an incomplete treatment.

The term Aqueous humor misdirection was introduced by Pederson and refers to the aqueous humor flux through an altered anterior hyaloid, in this case, caused by the RDD. Management has been proposed to be initially medical, then, if the eye is pseudophakic a LASER hyaloidotomy can be performed and finally a vitrectomy-hyaloidotomy-iridotomy has been shown to resolve the condition.

\section{Conclusions}

To our knowledge there are no reports on aqueous misdirection syndrome associated to a RDD. Both entities are potentially blinding and demand immediate treatment. Diagnostic approach and treatment shall be performed by experts and postoperative vigilance must be strict due to possible complications.

\section{References}

1. Mandal AK, Chakrabarti D, Chakrabarti R (2014) Shallow Anterior Chamber. In: Glaucoma: Second Edition.

2. Ruben S, Tsai J, Hitchings RA (1997) Malignant glaucoma and its management. Br J Ophthalmol 81(2): 163-167.

3. Shahid H, Salmon JF (2012) Malignant glaucoma: a review of the modern literature. J Ophthalmol 852659.

4. Guidelines E (2017) European Glaucoma Society Terminology and Guidelines for Glaucoma, (4th edn.), - Part 1. Br J Ophthalmol.

5. Sharma A, Sii F, Shah P, Kirkby GR (2006) Vitrectomyphacoemulsification-vitrectomy for the management of aqueous misdirection syndromes in phakic eyes. Ophthalmology 113(11): 1968-1973.

6. Dada T, Gadia R, Sharma A, Parul Ichhpujani, Shveta Jindal Bali et al (2011) Ultrasound biomicroscopy in glaucoma. Surv Ophthalmol 56(5): 433-450.

7. Jacobsen B, Lahham S, Lahham S, Patel A, Spann S, Fox JC (2016) Retrospective Review of Ocular Point-of-Care Ultrasound for Detection of Retinal Detachment. West J Emerg Med 17(2): 196-200.

8. Kirchhof B, Oh KT, Hartnett ME, Landers MB (2012) Pathogenetic Mechanisms of Retinal Detachment. In: Retina (5th edn.),

9. van Heuven WA, Lam KW, Ray GS (1982) Source of subretinal fluid based on ascorbate analyses. Arch Ophthalmol 100(6): 976-978.

10. Hayden BC, Kelley L, Singh AD (2008) Ophthalmic Ultrasonography: Theoretic and Practical Considerations. Ultrasound Clinics.

11. Tabibian D, Hoogewoud F, Mavrakanas N, Schutz JS (2015) Misdirected aqueous flow in rhegmatogenous retinal detachment: a pathophysiology update. Survey of Ophthalmology 60(1): 51-59.

12. Dave P, Senthil S, Rao HL, Garudadri CS (2013) Treatment outcomes in malignant glaucoma. Ophthalmology 120(5): 984-990.

\begin{tabular}{l} 
Your next submission with Juniper Publishers \\
will reach you the below assets \\
- Quality Editorial service \\
- Swift Peer Review \\
- Reprints availability \\
- E-prints Service \\
- Manuscript Podcast for convenient understanding \\
- Global attainment for your research \\
- Manuscript accessibility in different formats \\
( Pdf, E-pub, Full Text, Audio) \\
- Unceasing customer service \\
Track the below URL for one-step submission \\
https://juniperpublishers.com/online-submission.php \\
\hline
\end{tabular}

